\title{
USING VOLUME OF CONCEPT IN THE CLASS ENVIRONMENT
}

\author{
Salih Gülen (iD \\ Dr. Ministry of Education (Turkey) \\ sgnova@windowslive.com
}

Received March 2018

Accepted April 2018

\section{Abstract}

One of the tools that indicate the relationship between concepts is the volume of concept. Volume of concept is displayed that the relations between the concepts of the subject are exhibited in a meaningful harmonious and circular manner in a certain order. The purpose of this research; to be able to determine the usefulness volume of concept, from association tools of concept, in educational process. A mixed method was used in this study. Frequency and percentage values were calculated using comparative samples in the quantitative aspect of the study. In the qualitative aspect of work was used structured interview form, face to face interviews which were identified to code-categories and analyzed the data. As a result of the work, students had difficulty in drawing the volume of concept but they had expressed that the volume of concept was clearer. Moreover, it was determined that the rate of preference volume of concept during the exam was low. It can be said that use of the readymade form of the volume of concept was increases although a small proportion of students prefer concept volume when presented in the same way with another tools. Various suggestions have been made as a result of the research.

Keywords - concept, volume of concept, concept map, association tools of concept.

\section{Introduction}

Concepts are the building blocks of information we are thinking in our system. Concepts are expressions anything exists in the universe that meaningfulness or coding in mental (Demirkuş, 2017a; Gülen, 2010). Concepts as part of our daily life are units of thought that are classified as a systematic unity in the education and training process (Gökkurt Özdemir, Bayraktar \& Yılmaz, 2017). These units provide a mental change (Bellah, Robinson, Kaufman, Akers, Haase-Wittler \& Martindale, 2008). This change is defined as "learning" so the relevance of the learned concepts has also emerged (Yağbasan \& Gülçiçek, 2003).

The researchers aimed to reveal the relationship between concepts with developed tools such as concept map, concept network, concept analysis table, concept song, concept cluster and volume of concept to use them in education and training process (Demirkuş, 2017b; Gülen, 2016). Because with the help of association tools of concept could took place creating a visual unity of relations between concepts in the learning process of the subject and could formation of the mental schemes of the learning individual (Celik, 2016; Gülen \& Demirkus, 2014). Also Taş, Gülen, Öner and Özyürek (2015) found that students understood the relation between these concepts better by explaining the concepts using different methods, techniques and different association tools of concept.

Association tools of concept was attempted to been detected to effect of used to strengthen relationship between concepts for learning process in the process of education and training. It has been determined in the 1970s that the information about the concept map discovered by Novak et al. (trans, Güçlüler, 2006) can be used 
in the concrete and visual arrangement and presentation (Kaptan, 1998). In addition, many more studies on the concept map have been made (Demirkuş, Bozkurt \& Gülen, 2017; Doğanay, 2017; Erickson, Lanning \& French, 2017). It can be noticed that any other association tools of concept has gone through similar paths. Gulen $(2015 ; 2016)$ had been working on a new association tools of concept called "volume of concept" inspired by a subject in the science textbook.

Volume of concept is displayed that the relations between the concepts of the subject are exhibited in a meaningful harmonious and circular manner in a certain order (Gülen, 2015; 2016). As the author shows below the conceptual volume of the unit constitute circularly starting with the most inclusive of subject concepts on an agreed-upon level of involvement.

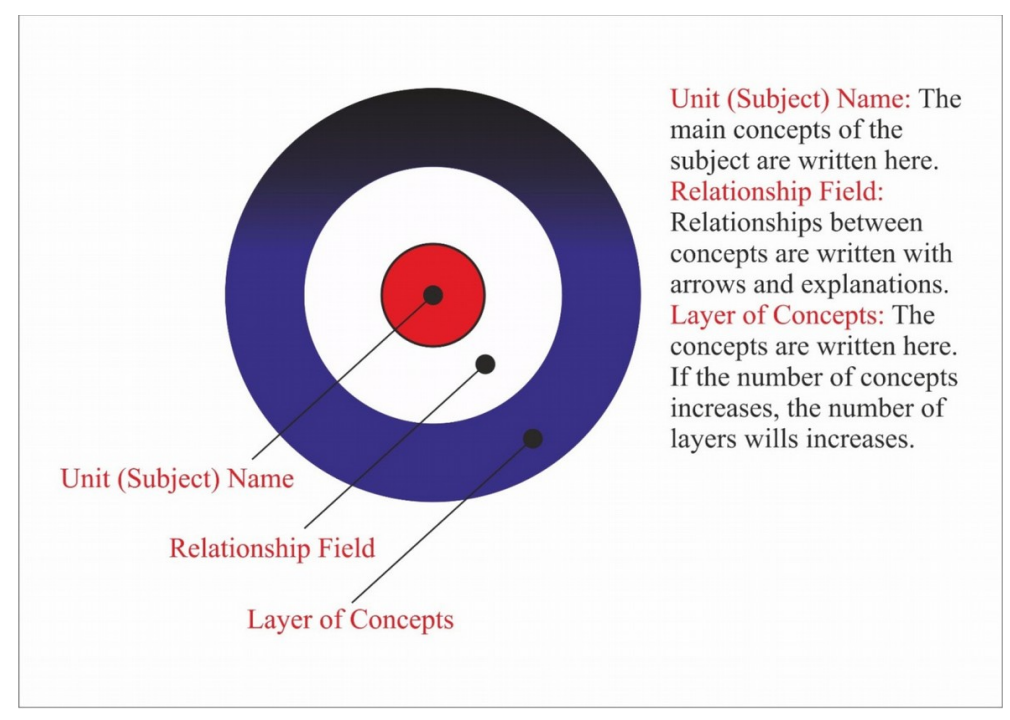

Figure 1. The Template Volume of Concept

Volume of concept is used to determine the concepts within the subject and the relationship between these concepts. Also helps to get the following judgements.

1. The most inclusive concepts are those near the center.

2. The larger volume of concept, the more subject matter is examined in depth.

3. Volume of concept can be used in the summary of the subject.

4. Volume of concept can be provided a simpler understanding of the subject.

When the above information and the example given below are examined, it is understood that this concept can be used in education process (Gülen, 2015, 2016).

In Figure 2, it is expected that students will make a volume of concept using subject concepts. This has already been given necessary training. The result is as shown in Figure 2. Figure 2 shows the student's freelance study in the Matter and Features section, without the student being given a pre-prepared form. Figure 3 shows the study of the System in our Body by giving the student pre-prepared form. In Figure 3, it is expected that the student will make a volume of concept using the concept of the subject. But this time it is desirable to use the ready form. This has already been given necessary training. These examples summarize the progress made in volume of concept in the process. 


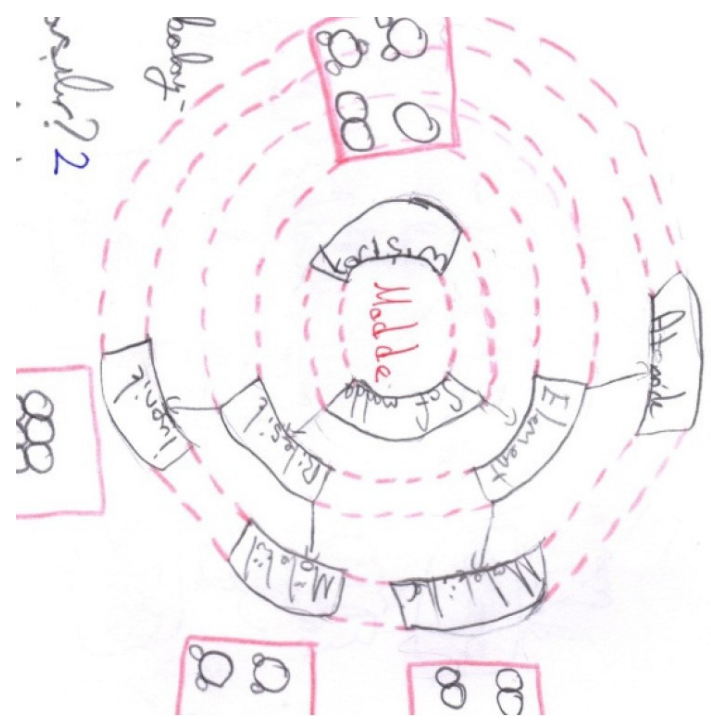

Figure 2. Study of freelance

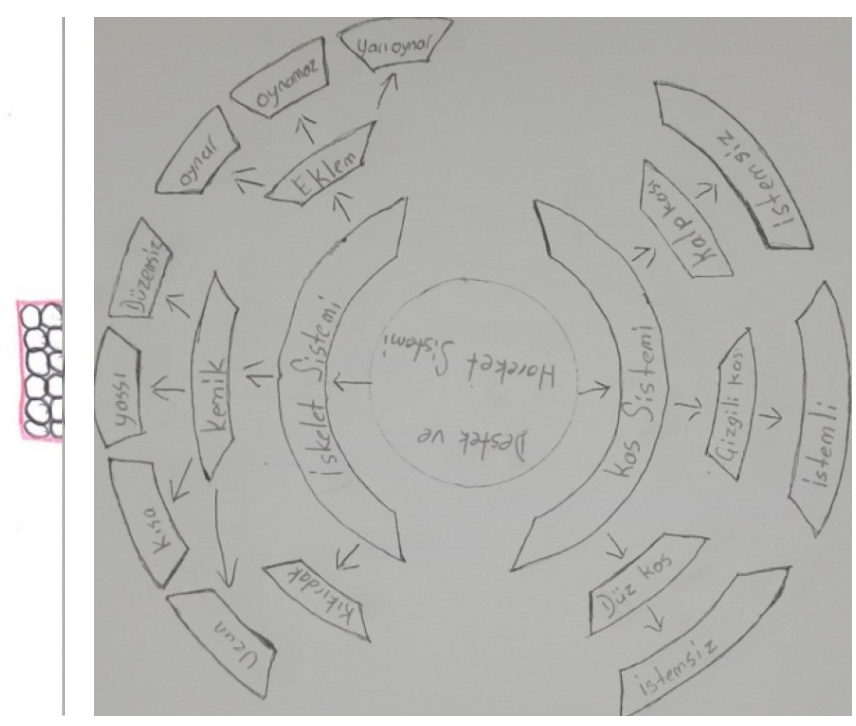

Figure 3. Study of pre-prepared form

\subsection{The Importance of Research}

Because of the importance of the understanding of the relationships between concepts in the process of education, Association tools of concept need to be used in the educational process. In this research, the use of the association tool, called volume of concept, prepared by Gülen (2015) is important for the usefulness in the class environment. This research will be an example for who are working on concepts and association tools of concept. Research use volume of concept in the educational setting for the example study. Volume of concept can be used to summarize the subject concepts and determine the relationship between them. It is thought to be a source of inspiration for future works by going out of this research.

\subsection{Purpose of the Research}

The purpose of this research, one of the association tools of concept is volume of concept be able to determine the usefulness in the education-training process. During the lesson, the question of conceptuality and the results are intended. Also collect evidence with comparative examples.

\subsection{The Problem of Research}

What is the use volume of concept in the educational process? In order to find the answer to this main problem, the following four sub-problems must be solved.

1. What are the views of students on the use of volume of concept? With the solution of this problem, students will have access to their thoughts on volume of concept.

2. What is the use rate of volume of concept in the written exams of the students and why? With the solution of this problem, students will learn volume of concept usage rate and its reason in the written exam.

3. When the volume of concept is given to the students in ready format, what is the usage rate and why? When the ready format of the volume of concept is given to the students, the usage rates and the reasons will be learned.

4. What are the usage ratios when the volume of concept and concept map are given ready forms? When the volume of concept and concept map ready format is given to the students, the usage rates will be learned. 


\section{Method}

A mixed method was used in this study. Creswell (2006) combines the basic proposal of a mixed method to use quantitative and qualitative approaches together to better understand research problems than to use both approaches alone. By using the mixed method, it is necessary to present both the numerical values of the data obtained from the participants and to try to have information about their causes. In this study, frequency and percentage values were calculated using comparative samples in the quantitative aspect of the study. Quantitative data provides a numerical comparison of the research. In the qualitative dimension of the study, the structured interview form and face-to-face interviews were conducted to identify codecategories for analyze the data. Qualitative data allows the reasons for preferences to be questioned.

The mixed method is difficult and requires expertise. The data must be examined and commented on by several people. It takes time and assumed that participants present objective data.

\subsection{Tools Used in Research}

Written test papers, volume of concept form and concept map form were used for quantitative data. For qualitative data, probes were used for interviews with a fully structured interview form. Speeches are recorded.

\subsection{Statistics}

Descriptive statistics were used in the study. The obtained data were objectively determined by two field experts. Forms and papers used in the study were prepared with the help of specialists. Used in the classroom environment. The ready-made forms were prepared to cover the subject concepts and examined according to the fact that the students placed the concepts correctly. Questions are designed to be open-ended. All the papers taken from the participants were coded and read. The data were obtained entirely with voluntary participation.

\subsection{Working Group}

The study was conducted at a village school in the Karadeniz zone. The study was conducted with 40 students in grades 6 and 7 of the school. Students were between 12-13 years (6th grade) and 13-14 years (7th grade). 6th and 7th graders also work with the same units at the same time. Although the main concepts of the units are the same, some concepts and concept numbers differ. It is assumed that this difference is not at a level that can negatively affect the study.

\subsection{Time}

The students were taught to conceptualize the relationship between concepts during a week. At the end of the subject, the use of the association tools of concept on exam papers was examined. Then interviews were made on their use. In the reconstructed data of the obtained data, the previously prepared "volume of concept" and "concept map" forms were used. The study lasted eight weeks in total.

\section{Findings and Comment}

The students are taught the concepts of conceptualizing the relationship between the concepts of "Matter and Features" unit. It was determined that these tools were drawn on the board by using volume of concept and concept maps, and students could make the same drawings on their notebooks (the same concepts were used in drawings). The interview (interview with the relevant students) on this subject (the fully structured interview form) has the following main points determined. The data in the tables (Table 1 to 5) were obtained by interpreting two separate field experts. After the first field expert examined the papers, the second field examined the expert. Then the data were compared and a common result was reached. Comments are assumed to be independent and objective. 


\begin{tabular}{|c|c|c|c|c|c|c|c|c|}
\hline \multirow{3}{*}{$\mathrm{N}: 40$} & \multicolumn{4}{|c|}{ Concept map } & \multicolumn{4}{|c|}{ Volume of concept } \\
\hline & \multirow{2}{*}{$\begin{array}{c}\text { 7th } \\
\text { grades }\end{array}$} & \multirow{2}{*}{$\begin{array}{c}\text { 6th } \\
\text { grades }\end{array}$} & \multicolumn{2}{|c|}{ Total } & \multirow{2}{*}{$\begin{array}{c}\text { 7th } \\
\text { grades }\end{array}$} & \multirow{2}{*}{$\begin{array}{c}\text { 6th } \\
\text { grades }\end{array}$} & \multicolumn{2}{|c|}{ Total } \\
\hline & & & f & $\%$ & & & f & $\%$ \\
\hline Which one are you having difficulty writing? & 3 & 0 & 3 & 11 & 14 & 10 & 24 & 89 \\
\hline Which is clearer? & 7 & 0 & 7 & 24 & 10 & 12 & 22 & 76 \\
\hline Which makes your learning easier? & 3 & 10 & 13 & 50 & 11 & 2 & 13 & 50 \\
\hline
\end{tabular}

Note: Some students responded both to the question or leave some questions blank

Table 1. Statistical value of the data obtained from the interview

Table 1 was prepared according to the answers of the questions asked to the students. The questions were written on paper and students were asked to write only volume of concept or concept maps in response to them. As shown in Table 1,89\% of the students were related to the two concept association tools prepared with the same concepts and drawn on the board stated that it was difficult to draw the volume of concept, but $76 \%$ of the students found the volume of concept to be more understandable. In addition, students have equal preference for both tools in facilitating learning.

In the written examination after the above studies, the students were given basic concepts related to the "Matter and Features" unit and they were asked to determine the relations between them by using the volume of concept or concept map they had previously learned. The statistical table related to the association tool of concept used by the students in the written examination is as follows.

\begin{tabular}{|c|c|c|c|c|c|c|c|c|}
\hline \multirow{3}{*}{$\mathrm{N}: 40$} & \multicolumn{4}{|c|}{ Concept map } & \multicolumn{4}{|c|}{ Volume of concept } \\
\hline & \multirow{2}{*}{$\begin{array}{c}\text { 7th } \\
\text { grades }\end{array}$} & \multirow{2}{*}{$\begin{array}{c}\text { 6th } \\
\text { grades }\end{array}$} & \multicolumn{2}{|c|}{ Total } & \multirow{2}{*}{$\begin{array}{c}\text { 7th } \\
\text { grades }\end{array}$} & \multirow{2}{*}{$\begin{array}{c}\text { 6th } \\
\text { grades }\end{array}$} & \multicolumn{2}{|c|}{ Total } \\
\hline & & & f & $\%$ & & & f & $\%$ \\
\hline Number of drawings in written exam & 11 & 15 & 26 & 68 & 9 & 3 & 12 & 32 \\
\hline
\end{tabular}

Note: Some students did not draw on the answer sheet.

Table 2. Statistical values of the association tools of concept used by the students in the written exam

As seen in Table 2, only $32 \%$ of the students preferred the volume of concept during the written exam. As a result of interviews with the students of both grades, it was determined that criticism such as difficulty of oval drawings and taking time was the foreground in volume of concept. Some of the quotations from student interviews are as follows.

I did not choose it because I thought it would be difficult to draw the oval parts (7B5).

I thought you'd take the time because it's hard (6B3).

It's difficult to draw the concept (7G2).

Map more comfortable (6G4).

It can be seen from the student's explanations that the volume of concept is not preferred during the examination because of the reasons such as "difficulty", "worry" that the volume of concept will come from "oval" and the concept map seems more "comfortable" in drawing. The explanations also show that if the concept volume is provided for ease of drawing, it is thought that it can be used more easily in class environment. Therefore, after these studies, a concept map describing was drawn on the board relation between the concepts of "Systems in our Body" unit. Students are asked to draw only one of the following options.

A) Drawing concept map on A4 paper

B) Use of pre-prepared form of the volume of concept

The statistics of the results obtained from the preferred results are given in Table 3. 


\begin{tabular}{|c|c|c|c|c|c|c|c|c|}
\hline \multirow{3}{*}{$\mathrm{N}: 40$} & \multicolumn{4}{|c|}{ Concept map } & \multicolumn{4}{|c|}{ Volume of concept } \\
\hline & \multirow{2}{*}{$\begin{array}{c}7 \text { th } \\
\text { grades }\end{array}$} & \multirow{2}{*}{\begin{tabular}{|c|} 
6th \\
grades
\end{tabular}} & \multicolumn{2}{|c|}{ Total } & \multirow{2}{*}{$\begin{array}{c}7 \text { th } \\
\text { grades }\end{array}$} & \multirow{2}{*}{$\begin{array}{c}\text { 6th } \\
\text { grades }\end{array}$} & \multicolumn{2}{|c|}{ Total } \\
\hline & & & f & $\%$ & & & $\mathrm{f}$ & $\%$ \\
\hline Preferences & 5 & 1 & 6 & 20 & 11 & 13 & 24 & 80 \\
\hline
\end{tabular}

Note: There are non-attendance students in both classes.

Table 3. Statistics of the results obtained after the selection

As shown in Table 3, $80 \%$ of the students used the volume of concept tool provided in the pre-prepared form. From this, it can be said that during the lesson, the usage rate is increased by preference of the volume of concept given in the form of pre-prepared form from the drawing of the concept map. In order to question the reason for this finding, the following data were obtained from the students one by one.

\begin{tabular}{|c|c|c|c|c|}
\hline \multirow{3}{*}{$\mathrm{N}: 24$} & \multicolumn{4}{|c|}{ Volume of concept } \\
\hline & \multirow{2}{*}{ 7th grades } & \multirow{2}{*}{ 6th grades } & \multicolumn{2}{|c|}{ Total } \\
\hline & & & f & $\%$ \\
\hline Easier & 7 & 8 & 15 & 62.5 \\
\hline Enjoyable & 3 & 4 & 7 & 29.2 \\
\hline Saving time & 1 & 1 & 2 & 8.3 \\
\hline
\end{tabular}

Table 4. Reasons for choosing volume of concept

Table 4 is the result of interviews with students who prefer only volume of concept during the activity. According to the table, $62.5 \%$ of the students informed that the pre-prepared form of the volume of concept "easier" the drawing, 29.2\% "enjoyable" and 8.3\% provides "time saving". Based on these data, it can be said that the association tool of concept given in the pre-prepared form provides convenience for the student.

Finally, the concepts of "Systems in our Body" are written randomly without any relation between them on board. Students are required to draw only one of the pre-prepared "concept volume" or "concept map" forms. The results obtained are as follows.

\begin{tabular}{|c|c|c|c|c|c|c|c|c|}
\hline \multirow{3}{*}{$\mathrm{N}: 40$} & \multicolumn{4}{|c|}{ Concept map } & \multicolumn{4}{|c|}{ Volume of concept } \\
\hline & \multirow{2}{*}{$\begin{array}{c}7 \text { th } \\
\text { grades }\end{array}$} & \multirow{2}{*}{$\begin{array}{c}\text { 6th } \\
\text { grades }\end{array}$} & \multicolumn{2}{|c|}{ Total } & \multirow{2}{*}{$\begin{array}{c}7 \text { th } \\
\text { grades }\end{array}$} & \multirow{2}{*}{\begin{tabular}{|c|} 
6th \\
grades
\end{tabular}} & \multicolumn{2}{|c|}{ Total } \\
\hline & & & $\mathrm{f}$ & $\%$ & & & $\mathrm{f}$ & $\%$ \\
\hline Frequency of use & 14 & 5 & 19 & 63 & 2 & 9 & 11 & 37 \\
\hline
\end{tabular}

Note: There are non-attendance students in both classes.

Table 5. Statistical values of data obtained as a result of using pre-prepared forms

As shown in Table 5, when both forms of the association tool were given the pre-prepared form, $63 \%$ of the students selected the concept map and $37 \%$ of them selected the volume of concept. From this finding, it can be said that when both concept linking tools are given in pre-prepared format, majority of students use preferences in the concept map.

\section{Results and Discussion}

As a result of this study, it has been found that students have difficulty in drawing the volume of concept but that the volume of concept is more understandable. In addition, students have equal preference for both tools in facilitating learning. There is no sample work on the use of volume of concept in the educational environment. However, it should be noted that Akyürek (2003) and Tunam (2017) used concept maps as a teaching tool in their research and expressed that students understood better when they 
used this tool. It can be said that students are in similar sentiments about the volume of concept if they go out from the results of this research.

According to another result of the research, it was determined that the students preferred the concept map to the volume of concept. It has been determined that oval drawings of volume of concept are difficult for the result of the interviews made to the students and therefore the loss of time will affect student preferences. Moreover, according to the students, the result of the concept map is more comfortable than the volume of concept. In Romero, Cazorla and Buzon (2017), they aimed to learn the concept maps in the second stage and found that this goal was achieved as a result of the study. They found the availability of the concept map in the classroom environment. As seen in this study, the volume of concept can be learned as well as learning the concept map but there is no study about volume of concept.

There is no comparative example of volume of concept in the literature, but researchers such as Ayaz and Demirkuş (2017), Kutluca, Döner and Butakin (2017) have provided us with insight into the use of teaching and learning methods by comparing association tools of concept with each other and with traditional methods. As a result, it can be said that the majority of the students do not prefer volume of concept during the exam.

Students are given a pre-prepared form for increase the rate of preference volume of concept during the lesson, based on the reasons for the preferences of the students during the exams. It has been determined that the vast majority of students prefer volume of concept to concept map which is given pre-prepared form for the drawing. As a reason for this, students expressed the ease of drawing the volume of concept with pre-prepared form, making it enjoyable and saving time. Based on these data, it can be said that association tools of concept given in the pre-prepared form provides convenience for the student. Tezcan, Karakuzu and Ekmekçi (2011) determined that concept map provided facilities for the students in their studies. It also expresses satisfaction that students use the concept maps. It can be said that this study has similar results in our study.

Finally, it was found that when both the concept map and volume of concept with pre- prepared form were presented to the students, most students favored the preferences of the concept map. It can be said that when these two association tools of concept are given in the pre-prepared format, the number of students who use volume of concept is less than the number of students who use the concept map. Talaslioğlu and Şahin (2018) found that the relationship between graphic literacy and decision-making skills and concept learning was positive. Similarly, the ready-made forms used in this study are thought to facilitate the learning of concepts by students.

\section{Conclusions}

It has been found that students have difficulty in drawing the volume of concept but that the volume of concept is more understandable. Because of oval drawings and loss of time the students preferred the concept map to the volume of concept. When students are given a pre-prepared form for increase the rate of preference volume of concept during the lesson, vast majority of students prefer volume of concept to concept map. Also, it was found that when both the concept map and volume of concept with pre- prepared form were presented to the students, most students favored the preferences of the concept map.

The following suggestions can be given by going to the end of this study. Volume of concept can be used during the lesson. The concept volume can be presented in ready-made format to prevent students from worrying about drawing and time loss. The preference rate can be increased by presenting concept volume in the ready format. The concept of volume visually and interest can be used to increase the use of the classroom environment. 


\section{Declaration of Conflicting Interests}

The author declared no potential conflicts of interest with respect to the research, authorship, and/or publication of this article.

\section{Funding}

The author received no financial support for the research, authorship, and/or publication of this article.

\section{References}

Akyürek, S. (2003). Use of concept maps in religion culture and moral knowledge lessons. Journal of Values Education, 1(3), 65-85.

Ayaz, M., \& Demirkuş, N. (2017). Example Works in the Development of Course Materials in Science Course Using Virtual and Objective Technological Teaching Tools. YYU Journal of Education Faculty, 14(1), 1257-1376.

Bellah, K.A., Robinson, J.S., Kaufman, E.K., Akers, C., Haase-Wittler, P., \& Martindale, L. (2008). Brainbased Learning: A Synthesis of Research. Journal of North American Colleges and Teachers of Agriculture, 52(2), 15-22.

Celik, H. (2016). An examination of cross sectional change in student's metaphorical perceptions towards heat, temperature and energy concepts. International Journal of Education in Mathematics, Science and Technology, 4(3), 229-245. https://doi.org/10.18404/ijemst.86044

Creswell, J.W. (2006). Understanding Mixed Methods Research, (Chapter 1). Available at: http://www.sagepub.com/upm-data/10981 Chapter 1.pdf

Demirkuş, N. (2017a). Important concepts in biology lecture notes. Yüzüncü Y1l University. http://www.biyolojiegitim.yyu.edu.tr/ders/kav.htm (Accessed: December 2017)

Demirkuş, N., (2017b). Teaching material development course notes. Yüzüncü Yıl University. http://biyolojiegitim.yyu.edu.tr/ders/otm.htm (Accessed: February 2017)

Demirkuş, N., Bozkurt, T., \& Gülen, S. (2017). The Study of Development Visual Material in Education on Popular Environmental Concepts. Journal of Abi Evran University Krrşebir Education Faculty, 18(Special Issue), 145-157.

Doğanay, A. (edt) (2017). Teaching Principles and Methods. Ankara: Pegem Akademi Publishing.

Erickson, H.L., Lanning, L.A., \& French, R. (2017). Concept-Based Curriculum and Instruction for the Thinking Classroom. California: Corwin Publisher

Gökkurt Özdemir, B., Bayraktar, R., \& Yılmaz, M. (2017). Explanations of Primary and Middle School Mathematics Teachers on Misconceptions. Journal of Trakya University Education Faculty, 7(2), 284-305. https://doi.org/10.24315/trkefd.284301

Güçlüler, E.(2006). The influence of cognitive support given by concept maps in primary school science education to remember success and bold on science lesson. Unpublished Master's Thesis. Dokuz Eylül University Educational Sciences Institute, Izmir.

Gülen, S. (2010). Development of visual lesson material including popular physics concepts. Unpublished Master Thesis, Yüzüncü Yıl University Institute of Science. Van.

Gülen, S. (2015). Tool of Association Concept; Volume of Concept. II. International Dynamic, Explorative and Active Learning (IDEAL) Conference. Amasya, Turkey. 
Gülen, S. (2016). Tool of Association Concept; Volume of Concept. Participatory Educational Research, Special Issue (II), 45-50. https://doi.org/10.17275/per.16.spi.2.5

Gülen, S., \& Demirkuş, N. (2014). The effect of visual material on student success. Saarbrücken: Turkey Alim Books.

Kaptan, F. (1998). The use of concept mapping method in science teaching. Journal of Hacettepe University Education Faculty, 14, 95-99.

Kutluca, T., Döner, M., \& Butakin, V. (2017). Evaluation of the Usability of Concept Maps When Teaching the Subject of Rational Numbers. Journal of Adiyaman University Educational Sciences, 7(1), 149-171. https://doi.org/10.17984/adyuebd.325361

Romero, C., Cazorla, M., \& Buzon O. (2017). Meaningful learning using concept maps as a learning strategy. Journal of Technology and Science Education, 7(3), 313-332. https://doi.org/10.3926/jotse.276

Talaslıoğlu, S.S., \& Şahin, F.(2018). Research on correlation and relationship between graphic literacy activities, decision making abilities and concept learning of third grade students. Journal of Human Sciences, 15(1), 62-76. https://doi.org/10.14687/jhs.v15i1.4709

Taş, E., Gülen, S., Öner, Z., \& Özyürek, C. (2015). The effects of classic and web-designed conceptual change texts on the subject of water chemistry. International Electronic Journal of Elementary Education, 7(2), 263-280.

Tezcan, H., Karakuzu, Z., \& Ekmekçi, G. (2011). Concept Maps in the Conception of Matter and Properties. Effect of Assisted Instruction on Student Success. Gazi University Gazi Education Faculty Journal, 31 (1), 156-193.

Tunam, A. (2017). The methods of used concept map and video taking for satisfaction of students in nursing teaching. Journal of Human and Social Sciences Research, 6(3), 1863-1875.

Yağbasan, R., \& Gülçiçek, Ç. (2003). Defining the characteristics of concept misconceptions in science teaching. Journal of Pamukeale University Education Faculty, 1(13), 102-120.

Published by OmniaScience (www.omniascience.com)

Journal of Technology and Science Education, 2018 (www.jotse.org)

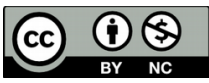

Article's contents are provided on an Attribution-Non Commercial 4.0 Creative commons International License. Readers are allowed to copy, distribute and communicate article's contents, provided the author's and JOTSE journal's names are included. It must not be used for commercial purposes. To see the complete licence contents, please visit https://creativecommons.org/licenses/by-nc/4.0/. 